\title{
Neurodynamical model of confidence decision-making in LIP
}

\author{
Andrea Insabato ${ }^{1 *}$, Mario Pannunzi ${ }^{1}$, Gustavo Deco ${ }^{1,2}$ \\ From Twentieth Annual Computational Neuroscience Meeting: CNS*2011 \\ Stockholm, Sweden. 23-28 July 2011
}

Decision confidence, the degree of certainty to which a subject believes his choice is correct, is an emerging subject in neuroscience. On one hand it is a fundamental component of our subjective conscious experience. On the other hand it is crucial to many cognitive functions like action planning and learning. In the past the speed accuracy trade-off in decision-making has received much attention by the scientific community since it is a key aspect of simple decisions, used in experimental conditions. In the context of complex more "real" environments, where different strategies can be applied, besides speed and accuracy, flexibility also become very important. Flexibility is the ability of an agent to explore and use alternative strategies in order to reach the goals. In a more simple view flexibility is the ability of taking into account more options in a decision process. The selection between alternative strategies can be regulated by evaluating the confidence in a choice. If the confidence is too low and other strategies are available, then the subject will try an alternative. Therefore evaluating the confidence in a choice can be particularly helpful for agents in complex dynamic environments.

There is only few evidence about neural mechanisms underlying decision confidence [1][2]. New neurophysiological evidence about decision confidence comes from a recent study [3], that tested the ability of monkeys to choose, in a two choice random dot motion (RDM) task, between standard targets and a "sure" target appearing later. This target represents a small but certain reward. Recordings from LIP neurons during the behavioral task show a dependence of firing rate upon certainty in the decision.

We propose a theory about neuronal mechanisms of flexibility that can account for LIP data. The theory is

\footnotetext{
* Correspondence: andrea.insabato@upf.edu

${ }^{1}$ Center for Brain and Cognition, University Pompeu Fabra, Barcelona, Spain Full list of author information is available at the end of the article
}

implemented in a network model composed of integrate-and-fire neurons with biologically detailed synapses, including AMPA, NDMA and GABA receptors [4].

Our proposal is that, as reported by [2], the confidence is implicitly encoded in the firing-rate of the decision neurons, but there is no need for a reading out of this information. In our model the RDM stimulus generates a competition between two pools of decision neurons, a third pool remains silent until it is turned on by the third target presentation. When all three pools receive task salient stimulus they compete until a decision is reached. In this way the information about confidence in the first decision, stored in the firing-rate, is directly used into the network without the need of an other reading network [2].

We analyze the property of the network in a reduced mean-field model. The first bifurcation in the space of input is connected with speed accuracy trade-off [5]. Our finding is that the proximity with a second bifurcation enhances flexibility, raising the probability of alternative strategies.

\section{Acknowledgements}

This work was supported by the European Community's Seventh Framework Programme FP7/2007-2013 under grant agreement number 214728-2.

\section{Author details}

${ }^{1}$ Center for Brain and Cognition, University Pompeu Fabra, Barcelona, Spain. ${ }^{2}$ ICREA, Barcelona, Spain.

Published: 18 July 2011

\section{References}

1. Kepecs A, Uchida N, Zariwala HA, Mainen ZF: Neural correlates, computation and behavioural impact of decision confidence. Nature 2008, 455:227-231.

2. Insabato A, Pannunzi M, Rolls ET, Deco G: Confidence related decision making. J Neurophysiol 2010, 104:539-547.

3. Kiani R, Shadlen MN: Representation of confidence associated with a decision by neurons in the parietal cortex. Science 2009, 324:759-764. 
4. Wang XJ: Probabilistic decision making by slow reverberation in cortical circuits. Neuron 2002, 36:955-968.

5. Roxin A, Ledberg A: Neurobiological Models of Two-Choice Decision Making Can Be Reduced to a One-Dimensional Nonlinear Diffusion Equation. PLoS Comput Biol 2008, 4(3).

doi:10.1186/1471-2202-12-S1-P65

Cite this article as: Insabato et al:: Neurodynamical model of confidence decision-making in LIP. BMC Neuroscience 2011 12(Suppl 1):P65.

Submit your next manuscript to BioMed Central and take full advantage of:

- Convenient online submission

- Thorough peer review

- No space constraints or color figure charges

- Immediate publication on acceptance

- Inclusion in PubMed, CAS, Scopus and Google Scholar

- Research which is freely available for redistribution

Submit your manuscript at www.biomedcentral.com/submit
C Biomed Central 